SHORT REPORT

\title{
Effect of dietary advice to increase fruit and vegetable consumption on plasma flavonol concentrations: results from a randomised controlled intervention trial
}

\author{
R R Huxley, M Lean, A Crozier, J H John, H A W Neil, for the Oxford Fruit and Vegetable Study \\ Group
}

A recent meta-analysis of prospective cohort studies suggests that high dietary intakes of flavonols are associated with a significantly lower risk of coronary heart disease mortality. ${ }^{1}$ The major dietary sources of flavonols such as quercetin, kaempferol, and isorhamnetin are tomatoes, onions, kale, broccoli, celery, apples, and cherries, while catechins are concentrated in tea and red wine. ${ }^{23}$ No clinical trials have examined the effect of interventions to increase habitual fruit and vegetable intake on plasma flavonol concentrations in free living populations. As the principal dietary sources of flavonols are restricted to a few specific food types, it is uncertain whether general dietary advice to increase fruit and vegetable consumption will increase plasma flavonol concentrations. We conducted a randomised controlled trial to investigate the effect over six months of an intervention to increase fruit and vegetable intake in a free living population and investigated what impact this intervention had on plasma concentrations of flavonols. ${ }^{4}$

\section{METHODS}

The methods are outlined in more detail elsewhere. ${ }^{4}$ In brief, we undertook a randomised six month parallel group controlled trial using a brief negotiation model to encourage increased consumption of fruit and vegetables to at least five portions per day among 690 healthy subjects aged 25 to 64 years in Oxfordshire, UK. All those randomised were invited to attend two appointments six months apart with a trained research nurse at the health centre. Before each of the two appointments, the participants completed a questionnaire containing the previously validated Dietary Instrument for
Nutrition Education (DINE, a food frequency questionnaire with nine items). ${ }^{5}$ At both visits a $10 \mathrm{ml}$ non-fasting venous blood sample was taken for measurement of flavonols (the sum of quercetin, kaempferol, and isorhamnetin). Statistical analysis was restricted to those people for whom flavonols were detected at both baseline and follow up (128 of 668, $19 \%)$. Student's $t$ test and $\chi^{2}$ analyses were performed to compare general characteristics of people in the control and intervention groups. Changes in mean concentrations of plasma flavonols, and fruit and vegetable intakes, from baseline to follow up, between groups, were compared using the Mann-Whitney test, and the Wilcoxon test was used to compare changes within the groups.

\section{RESULTS}

There was no difference in sex, age, body mass index, blood pressure, social class, non-fasting plasma flavonol concentrations both at baseline and at follow up, or self reported number of fruit and vegetable portions consumed per day, between the groups (table 1), but the number of current smokers was significantly lower in people in the control group for whom flavonols were detected $(3.6 \% \vee 16.7 \%$, $\mathrm{p}=0.04)$. At follow up, participants in the intervention group showed a significant increase of 1.4 portions (3.5 to 4.9 portions $p<0.001)$ in the mean intake of fruits and vegetables, whereas there was no change in the control group $(\mathrm{p}=0.56)$. There was no change in total non-fasting plasma flavonol concentrations between baseline and follow up in either the control or intervention group $(p=0.70$ and $\mathrm{p}=0.12$, respectively).

Table 1 Comparison of characteristics between particpants in the control and intervention groups for whom flavonols were detected in non-fasting plasma samples at both baseline and at six month follow up

\begin{tabular}{|c|c|c|c|}
\hline & $\begin{array}{l}\text { Control } \\
(n=58)\end{array}$ & $\begin{array}{l}\text { Intervention } \\
(\mathrm{n}=70)\end{array}$ & $\begin{array}{l}\text { p Value for difference } \\
\text { between groups }\end{array}$ \\
\hline Sex (male\%) & 48 & 44 & 0.65 \\
\hline Age (y) & 45.8 & 46.3 & 0.74 \\
\hline BMI $\left(\mathrm{kg} / \mathrm{m}^{2}\right)$ & 25.7 & 24.9 & 0.26 \\
\hline Mean SBP (mm Hg) & 130.6 & 125.9 & 0.15 \\
\hline Current smokers (\%) & 3.6 & 16.7 & 0.04 \\
\hline $\begin{array}{l}\text { Social class (\% in groups 1,2, } 3 \\
\text { (non-manual) }\end{array}$ & 62 & 69 & 0.96 \\
\hline $\begin{array}{l}\text { Number of daily portions of fruit } \\
\text { and vegetables at baseline }\end{array}$ & 3.0 & 3.5 & 0.07 \\
\hline $\begin{array}{l}\text { Number of daily portions of fruit } \\
\text { and vegetables at follow up }\end{array}$ & 3.2 & 4.9 & $<0.001$ \\
\hline $\begin{array}{l}\text { Total plasma concentration of } \\
\text { flavonols at baseline }(\mathrm{ng} / \mathrm{ml})\end{array}$ & 9.2 & 10.4 & 0.89 \\
\hline $\begin{array}{l}\text { Total plasma concentration of } \\
\text { flavonols at follow up }(\mathrm{ng} / \mathrm{ml})\end{array}$ & 10.1 & 9.2 & 0.71 \\
\hline
\end{tabular}

BMI, body mass index; SBP, systolic blood pressure. 


\section{DISCUSSION}

This is the first report of a randomised controlled trial that has investigated the effect of an intervention to increase habitual fruit and vegetable intake on plasma flavonol concentrations in a free living population. The findings of this primary care intervention suggest that although general dietary advice to increase daily consumption of fruit and vegetables is moderately effective at increasing intakes of fruit and vegetables ${ }^{4}$ it results in little or no increase in plasma flavonol concentrations.

The use of biochemical assays may provide a more objective method of quantifying flavonol intake than relying on dietary records because of the wide variation in the flavonol content in many foods. ${ }^{6}$ In this study, however, flavonols were detectable in only one third of participants, which is likely to have reduced the power of the trial to detect differences in plasma flavonol concentrations between baseline and six months' follow up. The inability to detect flavonols in two thirds of participants both before and after intervention probably indicates an overall low level of consumption of flavonol rich foods in this population. It may also have been attributable, in part, to the timing of sampling. Flavonol absorption usually peaks one to two hours after consumption of the main meal, ${ }^{7}$ which would be expected to be in the evening. By contrast, breakfast would not be expected to be rich in flavonols, although tea would be a possible source. As the timing of sampling was not standardised in our trial, but was undertaken throughout the day, in many people the plasma concentrations are likely to have been below the level of detection of the assay. However, the randomised nature of this large trial ensures that the variability in timing of specimens is unlikely to have been significantly different between the control and intervention groups. Consequently, the mean individual differences between the two groups will be a valid estimate of the effects of the dietary intervention.

In summary, the results from this study suggest that dietary interventions aimed at increasing flavonol intakes should specifically highlight those foods, such as apples, tomatoes, tea, and red wine, which are rich sources of these potentially beneficial antioxidants.

\section{ACKNOWLEDGEMENTS}

We would like to thank L Youngman, S Clark, B Chukwurah, and the staff of the Clinical Trial Service Unit and Epidemiological Studies
Unit, University of Oxford for undertaking measurement of plasma cholesterol and lipid soluble antioxidants, and the Department of Clinical Biochemistry, Glasgow Royal Infirmary for measurement of ascorbic acid.

\section{Authors' affiliations}

R R Huxley, J H John, H A W Neil, Division of Public Health and Primary Care, Institute of Health Sciences, University of Oxford, Headington, Oxford, UK

M Lean, A Crozier, Plant Products and Human Nutrition Laboratory, Division of Biochemistry and Molecular Biology, Institute of Biomedical and Life Sciences, University of Glasgow, Glasgow, UK

Funding: the trial was supported by a grant from the British Heart Foundation and the Department of Health funded the plasma flavonol measurements.

The views expressed in this paper are those of the authors and not necessarily those of the Department of Health.

Conflicts of interest: none declared.

Correspondence to: Dr R Huxley, Institute for International Health, 144 Burren Street, Newtown, Sydney, NSW 2042, Australia;

rhuxley@iih.usyd.edu.au

Accepted for publication 28 August 2003

\section{REFERENCES}

1 Huxley RR, Neil HAW. The relation between dietary flavonol intake and coronary heart disease mortality: a meta-analysis of prospective cohort studies. Eur J Clin Nutr 2003;57:904-8.

2 Hertog MGL, Hollman PCH, Katan MB. Content of potentially anticarcinogenic flavonoids of 28 vegetables and 9 fruits commonly consumed in the Netherlands. Journal of Agriculture and Food Chemistry 1992;40:2379-83.

3 Hertog MGL, Hollman PCH, van de Putte B. Content of potentially anticarcinogenic flavonids of tea infusions, wines, and fruit juices. Journal of Agriculture and Food Chemistry 1993:41:1242-6.

4 John JH, Ziebland S, Roe LS, et al. A randomised controlled trial of a primary care intervention to increase fruit and vegetable consumption. Lancet 2002;359:1969-74.

5 Roe L, Strong C, Whiteside C, et al. Dietary intervention in primary care: validity of the DINE method for diet assessment. Fam Pract 1994;11:375-81.

6 Crozier A, Lean MEJ, MacDonald M, et al. Quantitative analysis of the flavonoid content of commercial tomatoes, onions, lettuce and celery. Journal of Agriculture and Food Chemistry 1997;45:590-5.

7 Noroozi M, Burns J, Crozier A, et al. Prediction of dietary flavonol consumption from fasting plasma concentration or urinary excretion. Eur J Clin Nutr 2000;54:143-9. 